\title{
Ignorancia deliberada, ignorancia no imputable y principio de legalidad
}

\author{
Willful Ignorance, Non-Imputable Ignorance \\ and Principle of Legality
}

María Clara Gabella*

Recibido: 5/6/2020

Evaluado: $31 / 7 / 2020$

Aceptado: 29/9/2020

\begin{abstract}
Resumen: El texto es una reconstrucción del debate generado en el número XIII de la Revista Discusiones, en torno a la ignorancia deliberada o willful ignorance en derecho penal. En particular, se analizan las opiniones de las/ os autoras/es acerca de la posibilidad de aplicar la teoría -de origen anglosajón- en sistemas jurídicos de tradición continental europeo y los reparos que efectúan ante la ausencia de disposiciones legales expresas que establezcan el modo en el que las conductas de quienes actúan con ignorancia deliberada o culpable debieran ser castigadas. Tales inquietudes, vinculadas al principio de legalidad, constituirán el punto a partir del cual se propone analizar aquellos casos a la luz de una disposición del Código Penal argentino. La misma regula los supuestos que excluyen de pena a un sujeto si, al momento del hecho, no hubiera podido comprender la criminalidad de su conducta por "ignorancia de hecho no imputable".
\end{abstract}

Palabras clave: Ignorancia deliberada, principio de legalidad, ignorancia de hecho no imputable.

\footnotetext{
Abogada. Especialista en Derecho Penal. Universidad Nacional del Sur, Bahía Blanca, Argentina. Correo electrónico: mclaragabella@gmail.com. Quiero agradecer especialmente a Anna Ritcher y a Juan Andrés Cumiz, por haber leído un borrador de este trabajo. Sus comentarios, correcciones y aportes resultaron sumamente valiosos y, sin duda, este texto es mejor luego de haber incorporado -algunas de todas- aquellas ideas y sugerencias.
} 
Abstract: This paper is a reconstruction of the debate generated in the XIII number of the Journal 'Discusiones' around willful ignorance in criminal law. It analyzes the authors' opinions about the possibility of applying the Anglo-Saxon theory in legal systems of continental European tradition and the objections that are made in the absence of express legal provisions that establish how the conducts of those acting with willful or deliberate ignorance should be punished. Such concerns, linked to the principle of legality, will constitute the point from which it is proposed to analyze those cases considering a disposition of the argentinean criminal code. It regulates the assumptions that exclude a person from punishment if, at the time of the act, could not have understood the criminality of the conduct due to "non-imputable ignorance of fact".

Keywords: Willful ignorance, principle of legality, non-imputable ignorance of fact.

\section{Introducción}

La teoría de la ignorancia deliberada estudia aquellos casos en los cuales una persona provoca su desconocimiento, o no realiza un esfuerzo por conocer, acerca de una determinada circunstancia y, de esa forma, procura una excusa con el objeto de eliminar o disminuir su responsabilidad en el resultado lesivo que provoca su conducta. ${ }^{1}$

Generalmente se discute su aplicación cuando debe decidirse si corresponde aplicar un castigo, y en su caso de qué tipo, a quienes participan en el transporte de objetos relacionados con el blanqueo de capitales, el tráfico de armas o de drogas, en supuestos de delincuencia económica-empresarial, contaminación del medio ambiente, terrorismo, entre otros. En torno a esta figura en el ámbito del derecho penal suelen debatirse varias cuestiones. Entre otros temas, mientras algunos analizan, desde el terreno de la filosofía moral, la importancia que debe asignarse a las intenciones o motivos de una persona que actúa bajo ignorancia deliberada a fin de definir qué tipo de reproche debe aplicársele, otros parten de enfoques epistémicos 
Ignorancia deliberada, ignorancia no imputable y principio de legalidad

acerca de la prueba de los estados mentales o actitudes proposicionales de la persona en relación a un determinado evento, tales como su aceptación, creencia o sospecha de la ocurrencia de un hecho específico en el mundo y cómo incide ello en el reproche moral y jurídico de su conducta. Incluso el debate acerca de si deben ser castigados los casos de ignorancia deliberada y a qué título, ha traído al centro de la escena la discusión sobre los fines y funciones de las normas de derecho penal. Y también, se han generado planteos relativos a la adecuación de la figura con el derecho positivo de aquellos países con sistemas jurídicos de tradición continental europea y su paralelismo con otras formas de atribuir responsabilidad subjetiva, reconocidas y aceptadas por la dogmática penal contemporánea.

Tales interesantes cuestiones, que indefectiblemente inciden unas en otras, fueron abordadas en el número XIII de la Revista Discusiones, a partir de un excelente trabajo de Ramón Ragués i Vallés titulado "Mejor no saber. Sobre la doctrina de la ignorancia deliberada en Derecho Penal", que mereció las agudas observaciones y comentarios de Alberto Puppo, Luis Greco, María Laura Manrique y Bernardo Feijoo Sánchez.

Aquí me propongo reconstruir de un modo muy sintético solo un aspecto del debate generado en virtud de las ideas desarrolladas en aquella edición, principalmente el referido a la necesidad de que exista una previsión expresa de la figura en el derecho positivo de los sistemas jurídicos en los cuales se pretenda aplicarla, a fin de no afectar el principio de legalidad. Este tema, probablemente el menos atractivo de todos los que se han planteado, constituye sin embargo un eje importante y central sobre el cual han de girar la mayoría de las elaboraciones de la dogmática penal. ${ }^{2}$

Luego, a partir de la reiterada inquietud de las/os autoras/es en torno a aquella cuestión, propongo analizar la teoría de la ignorancia deliberada a la luz de las normas previstas en el Código Penal argentino, en la disposi-

2 Sobre este tema ver (Nino, 1989, p. 29), para quien la actitud de los juristas de otorgarle preeminencia a la ley como fuente del derecho, ha sido una actitud constante desde la codificación hasta nuestros días y constituye una característica distintiva de la labor dogmática. También ver (Navarro, Manrique y Peralta, 2010, p. 53) quienes concluyen en el trabajo citado que el desapego de la dogmática contemporánea de las decisiones del legislador tiene consecuencias importantes para la justificación de sus propuestas, en torno a la posibilidad de fundamentar su verdad y discrepar genuinamente acerca de ellas. 
ción del artículo 34, inciso 1, donde establece expresamente que se excluye de pena a un sujeto si, al momento del hecho, no hubiera podido comprender la criminalidad de su conducta por "ignorancia de hecho no imputable”. Sostendré que, tomando en cuenta dicha mención expresa sobre la no punibilidad de la ignorancia de hecho no imputable, es plausible sostener que la ignorancia deliberada sí resulta punible en el sistema jurídico argentino, aunque quede pendiente definir el modo -dolo o culpa- en el que deba atribuirse la responsabilidad.

\section{La ignorancia deliberada y la importancia de su regulación legal expresa}

En el artículo que da inicio a la revista que comentamos, el profesor Ramón Ragués i Vallès (2013) desarrolla sus argumentos en favor de la doctrina de la ignorancia deliberada a partir de la exposición de ciertos ejemplos y casos resueltos por la jurisprudencia norteamericana y el Tribunal Supremo Español. Para el autor, todos los supuestos enunciados por él describen situaciones en las que una persona podía haber obtenido determinada información pero, por razones muy diversas, ha preferido no adquirirla y mantenerse en un estado de incertidumbre. Al efectuar la contrarréplica a las observaciones que formulan sus colegas académicos, Ragués precisa los casos de ignorancia deliberada a los que asigna verdadera importancia, esto es, aquellos en los que la persona decide no adquirir los conocimientos de una realidad que ni siquiera sospecha. Para ello explica que pueden darse -más frecuentemente de lo que uno cree- situaciones en las que se es consciente del potencial lesivo más o menos determinado de una conducta -u omisión- y se prefiere no hacer el esfuerzo necesario para precisar exactamente en qué consiste dicha lesividad y cuáles son las características cualitativas, cuantitativas o temporales del riesgo creado (Ragués i Vallés, 2013, pp. 139-166). Cuando el caso resulta de trascendencia jurídico penal, Ragués se pregunta cómo debe enfrentarse el derecho penal ante estas situaciones, en el marco de un sistema penal en el que la mayoría de los comportamientos penalmente prohibidos requiere por parte del sujeto el conocimiento de las características objetivas de su hecho. Más aún cuando 
Ignorancia deliberada, ignorancia no imputable y principio de legalidad

el conocimiento insuficiente o el error son causas de exención de responsabilidad, salvo los casos en los que expresamente se prevé el castigo de conductas realizadas sin dicho conocimiento, como sucede en los delitos imprudentes (Ragués i Vallés, 2013, p. 12).

En los sistemas continentales de influencia germánica -como la mayoría de los latinoamericanos o el español- supuestos como los descriptos, en los que una persona renuncia deliberadamente a conocer (o a conocer mejor) determinadas circunstancias de su conducta, suelen reconducirse a aquella modalidad de dolo denominada "dolo eventual" pues, pese a su renuncia a conocer, en tales casos el sujeto cuenta ya con un conocimiento básico suficiente para atribuirle tal forma de dolo. (Ragués i Vallés, 2013, p. 17)

Para el autor, el hecho de que la gran mayoría de los Códigos Penales no contenga una definición de dolo facilita que la jurisprudencia y la doctrina ajusten los contornos de esta figura según la respuesta punitiva que consideran adecuada para cada caso o grupo de casos. Sin embargo, el incluirlos bajo la figura del dolo eventual acarrea, según Ragués, dos grandes problemas: en primer lugar, la equiparación de las respuestas punitivas en cuanto a su gravedad, para casos muy distintos desde el punto de vista del grado de implicancia subjetiva del sujeto. En segundo término, no le convence la solución dada en casos de quien, de manera intencionada, hubiera evitado adquirir los conocimientos mínimos que requiere el dolo eventual, esto es, quien siquiera albergue una sospecha inicial. Esos son los supuestos que el autor denomina de ignorancia deliberada stricto sensu.

Ragués sostiene que, si bien el planteamiento mayoritario en el derecho continental considera que la falta de conocimiento de la concurrencia de un determinado comportamiento de los elementos de una figura delictiva impide considerar el hecho como doloso, circunstancia que lleva a la impunidad o, cuando la ley lo permita, a castigar la conducta a título de imprudencia, tal conclusión le parece insatisfactoria. Ello pues, no deja de resultarle extraño que quien hubiera evitado conocer esté en una situación de error o hubiera actuado de manera negligente. Para el autor, afirmar que en los ejemplos que cita concurre una situación de error o descuido no solo le resulta cuestionable respecto de las consecuencias jurídicas que 
comporta tal afirmación, sino que parece oponerse al propio uso cotidiano del lenguaje. Y, por otra parte, afirma que existen razones de peso para sostener, partiendo del propio derecho positivo, que rige en derecho penal un principio según el cual nadie puede invocar en su descargo la concurrencia de un contexto de exoneración que él mismo ha contribuido a generar con el objeto de eludir la norma (Ragués i Vallés, 2013, p. 155). Por ello, la vía que le parece más adecuada pasa por buscar -según sus propias palabrasun tratamiento específico para estas situaciones, que conduce a preguntarse bajo qué condiciones ellas merecen ser tratadas como supuestos de dolo.

Alberto Puppo (2013), al comentar el artículo de Ragués i Vallès, inicia su exposición haciendo referencia a la producción legislativa en materia de dolo, tanto del Código Penal Italiano como del Español, destacando la observación que hace el autor en cuanto a que es más fácil dilatar la imputación subjetiva hasta incluir casos de ignorancia deliberada cuando los códigos penales nada dicen, o dicen muy poco, acerca del dolo. ${ }^{3}$ Aun así, señala Puppo, el principio de legalidad penal parece constituir un importante obstáculo que se opone a una dilatación de la noción de dolo y afirma que: "Es precisamente el principio de legalidad lo que probablemente justifica la hostilidad de la doctrina (legalista) continental respecto de la doctrina anglosajona de la willful blindness..." (Puppo, 2013, p. 41). Explica que, como es sabido, la legalidad penal, en el ámbito anglosajón, tiende a ser concebida de forma menos estricta que por la doctrina penal continental pero que, a pesar de ello, la teoría de la ignorancia deliberada se ha impuesto en algunas decisiones del Tribunal Supremo, no sin suscitar fuertes críticas por afectar el principio (legalista) de culpabilidad.

Luego señala que el concepto de dolo sirve para conectar ciertos hechos con ciertas consecuencias jurídicas y que la intuición general es que aquellas son más negativas cuando se trata de conductas dolosas que cuando son fruto de la imprudencia. Destaca que la distinción entre culpa y dolo depende de

3 Sin embargo, Puppo deja en claro que el Código Penal Italiano parece no formar parte de la gran mayoría de los Códigos de tradición continental, ya que “...parece no dejar mucho espacio para el planteamiento de la ignorancia deliberada como fuente de imputación equiparada al dolo. Este resultado parece derivar de la combinación de las disposiciones en materia de error y de elementos psicológicos del delito.... Seguidamente analiza los artículos 42, 43 y 47 del Código Penal Italiano (Puppo, 2013, pp. 40-41). 
Ignorancia deliberada, ignorancia no imputable y principio de legalidad

lo que generalmente los sistemas penales suelen llamar el elemento subjetivo, moral o psicológico de la conducta y, en una primera observación acerca de los casos de ignorancia deliberada presentados por Ragués, Puppo deja claro que el elemento subjetivo en tales supuestos está estrechamente relacionado con un juicio de valor sobre la reprochabilidad moral de cierta conducta, entendiendo por esta algo más general que la mera conducta exterior, esto es, incluyendo el hecho de ignorar. Y ello da pie al autor para exponer que al ser relevantes las razones por las que una persona ignora determinada circunstancia, la reflexión sobre la ignorancia deliberada posee un carácter abiertamente moral, destacando a partir de un minucioso análisis su estructura epistémico-moral. Sus consideraciones, vinculadas al reproche moral del ignorante deliberado, en relación a las cuestiones -de hecho o de derechoque pueden resultar ignoradas, serán retomadas más adelante en este trabajo.

Por su parte, Luis Greco (2013) efectúa observaciones similares en torno al principio de legalidad. Señala que buena parte de los casos de ignorancia deliberada son en verdad casos de dolo eventual y, por ello, en su opinión, la figura es prescindible. A su vez, luego de elaborar una crítica muy precisa a las razones que justificarían la mayor punición de estos supuestos y a la relevancia que se otorga a las motivaciones del autor para justificar la aplicación de pena a título de dolo, expuestas por Ragués, sostiene que es inaceptable equiparar al dolo los casos de ignorancia deliberada en sentido estricto. Concluye el autor que la ignorancia deliberada en sentido estricto sólo puede ser considerada imprudencia. ${ }^{4}$

Si alguien viola su deber objetivo de cuidado/crea un riesgo jurídicamente desaprobado, por ejemplo realizando un adelantamiento peligroso y nada ocurre, el derecho no lo castiga por la tentativa,

4 Muy concretamente, Greco (2013, pp. 70-76) cuestiona la perspectiva comunicativa que defiende Ragués y sostiene que la razón por la cual el derecho prohíbe y castiga comportamientos no puede estar en lo que ellos comunican respecto de la vigencia de una norma y sí debe estar en el peligro que esos comportamientos representan para la subsistencia de un bien. Desde esa perspectiva, entiende el autor que queda clara la diferencia entre dolo e ignorancia deliberada. Asimismo separa las motivaciones de un lado y el dolo o la imprudencia por otro, afirmando que se encuentran en planos distintos. Por último, plantea una objeción dogmática vinculada a los casos de tentativa. 
también por la imposibilidad de distinguir aquí entre tentativa culposa de homicidio, lesiones o daño. (Greco, 2013, p. 76)

De cualquier manera, plantea la existencia de barreras legales para el reconocimiento de una ignorancia deliberada equiparable al dolo. En ese sentido, entiende que Ragués no valoró en profundidad el texto de la ley, que tanto en España (art. 14.1 C.P.) como en Argentina (art. 34.1 C.P.) contienen -según el autor- una regla expresa sobre el error de tipo, que determina que el desconocimiento de elementos del tipo excluye el dolo.

Vislumbro pocas posibilidades de releer dispositivos que dispongan que el error sobre el elemento del tipo excluya el dolo en el sentido de que errores sobre los elementos del tipo justifiquen el dolo. La tesis de la ignorancia deliberada puede, como máximo, ser sustentada de lege ferenda, como propuesta de reforma legislativa. (Greco, 2013, p. 77)

Estas palabras de Greco llevan a pensar si efectivamente tuvo en mente la legislación argentina de la ignorancia de hecho como un supuesto que excluye la punición, más allá del error de tipo al que alude. Y si, en esas pocas posibilidades de releer los dispositivos de otra manera, valoró la referencia del artículo 34.1 del C.P. citado, en virtud de la cual, para excluir de responsabilidad al agente, la ignorancia -como también el error- no le debe ser imputable.

También en Discusiones XIII, María Laura Manrique (2013) comentó la postura de Ragués i Vallès, dedicando un importante apartado a la cuestión de la ignorancia deliberada y su regulación expresa en los códigos penales. Aunque, como en el caso de Greco, tampoco se refirió a la "ignorancia de hecho no imputable" incluida en la legislación argentina. Manrique considera inaceptable la propuesta de Ragués que, ante la falta de regulación legal expresa de la ignorancia deliberada en lo códigos penales como forma de reproche, castiga a los supuestos que encuadran en ella asimilándolos a una conducta dolosa, antes que dejarlos impunes o con un castigo sensiblemente menor. Sostiene que el argumento de Ragués, al que denomina "tesis de la asimetría”, se basa en gran medida en el ámbito de libertad interpretativa que resulta del hecho de que no existen definiciones legales expresas que limiten el sentido de "dolo", "imprudencia", etc., y, por tanto, impongan una solución específica a los problemas de qué cuenta como dolo o imprudencia. 
Ignorancia deliberada, ignorancia no imputable y principio de legalidad

La tesis de la asimetría es explicada por Manrique como aquella en virtud de la cual, frente a definiciones legales expresas, los jueces no poseen libertad para apartarse de esos significados, pero en caso de que no existan definiciones, los jueces pueden desarrollar discrecionalmente propuestas interpretativas. En este último supuesto, la dogmática cumpliría un papel fundamental, suministrando argumentos específicos que limiten la arbitrariedad interpretativa (Manrique, 2013, p. 94). Sin embargo, para la autora, mientras la dogmática posee amplia libertad para desarrollar sus propuestas en el ámbito del conocimiento científico, los jueces no gozan de la misma libertad, dado que en virtud de compromisos derivados del imperio de la ley en el Estado de Derecho, ellos están vinculados por las decisiones del legislador. Los jueces tienen la obligación de justificar sus decisiones en esas normas existentes. Esta vinculación de los jueces y demás agentes que aplican el derecho exige fidelidad al modo o manera en que el legislador utilizó el lenguaje, y tiene contenido similar tanto en casos donde hay una definición legal de las palabras de la ley como en los casos donde esas definiciones no existen. En otras palabras -dice Manrique- a efectos de fundar sus decisiones en la ley, los jueces tienen que determinar en qué sentido el legislador efectivamente utilizó el término "dolo" "imprudencia", etc. (Manrique, 2013, p. 95-96; Navarro et al., 2010, p. 16).

Así, la autora se pregunta de qué manera se puede analizar el modo en que se usa un concepto como el de dolo en caso de que no exista una definición explícita. Y responde que, aun cuando no haya una respuesta concluyente, es posible señalar una manera paradigmática en la dogmática penal contemporánea. Pone como ejemplo que, para los autores que defienden la vinculación entre dolo y conocimiento, un indicio de que el legislador ha asumido esa conexión se encuentra en las razones que excluyen el dolo (Manrique, 2013, p. 97). Destaca que en el caso del código español o el argentino, en los que existe la figura del error, una consecuencia de lo que dijo el legislador es que si el agente posee una creencia equivocada o, incluso, no posee una creencia $\mathrm{x}$ en relación a cierto comportamiento, no se puede atribuir responsabilidad a título de dolo. Ello pues, según Manrique, si bien tal circunstancia no es una razón para afirmar que el dolo es solo conocimiento, sí es una razón para entender que el conocimiento forma parte del dolo. Por eso concluye que, aunque haya razones morales para reprochar de la forma 
más grave los casos de ignorancia deliberada, los códigos penales que poseen la figura del error, aunque no hubieran definido al dolo, establecen un límite para el reproche de esas conductas. En ese marco, una dogmática penal que asuma el valor del principio de legalidad debería insistir en la necesidad de una reforma legislativa para castigar a la ignorancia deliberada con la misma severidad que el dolo (Manrique, 2013, pp. 97-98).

Como se puede apreciar, las afirmaciones de Manrique -en el mismo sentido que Greco- son precisas. Parecieran dejar poco margen a la discusión en torno a la previsión en el Código Penal argentino de una forma o modo de atribuir responsabilidad que pueda contemplar las figuras que usualmente encuadran en la ignorancia deliberada. Sin embargo, sus ideas no dejan de plantearme algunos interrogantes. Esto, porque parece plausible o razonable justificar la regulación de las situaciones de ignorancia deliberada a partir de una interpretación literal, o de acuerdo al uso común de las palabras (Guastini, 2014, p. 109), del texto del art. 34 inciso 1 del C.P., dado que en esa disposición se hace referencia expresamente a la ignorancia de hecho no imputable para eximir de responsabilidad. Por la extensión de este trabajo solo puedo limitarme a señalar esa posibilidad normativa a partir del texto legal citado, que sirve -al mismo tiempo- para destacar la importancia que poseen en los análisis de dogmática penal las regulaciones legales particulares de los sistemas jurídicos, sobre las que pueden o pretenden usarse las herramientas o propuestas conceptuales que se desarrollan. Claro, aún restaría para dar solución a esta propuesta determinar si esa ignorancia de hecho debe ser (no) imputable a título de dolo o culpa. Pero, de todas maneras, considero que puede ofrecerse una interpretación literal razonable que permita plausiblemente sortear algunas de las críticas relacionadas a posibles afectaciones o tensiones con el principio de legalidad y justificar la regulación a partir de ese texto tanto de situaciones de ignorancia atribuibles a título de dolo, dolo eventual o culpa.

Finalmente, en el número de la revista forma parte también de la discusión Bernardo Feijoo Sánchez (2013), quien desde su visión normativa del dolo expone una opinión crítica de la doctrina de la ignorancia deliberada. ${ }^{5}$

5 Feijoo Sánchez luego reafirma su postura en un artículo similar al comentado, en el que realiza un análisis pormenorizado de la jurisprudencia del Tribunal Supremo Español. 
Ignorancia deliberada, ignorancia no imputable y principio de legalidad

Para el autor, la mayoría de los ejemplos propuestos por Ragués no presentarían problemas para ser calificados como dolo eventual. De hecho, más adelante en su exposición culmina por afirmarlo (Feijoo Sánchez, 2013, p. 122). La doctrina de la ceguera provocada o deliberada seguida por la jurisprudencia del Tribunal Superior Español intenta llegar -según el autor- a las mismas conclusiones, pero no trabajando sobre las exigencias del ordenamiento jurídico sobre lo que se debe conocer para responder de forma dolosa, sino cambiando el momento de la "intencionalidad". Para el derecho penal sería lo mismo, desde esta perspectiva, el desconocimiento provocado que el conocimiento. Nuevamente, entre los inconvenientes que trae aparejados la importación de la doctrina anglosajona de la willful blindness en sistemas jurídicos de tradición continental, Feijoo Sánchez (2013) advierte que: “...se trata de una doctrina que castiga con la pena del delito doloso saltándose las exigencias legales para tal modalidad...” (p. 109). Caben ser destacadas aquí las vinculaciones señaladas por el autor entre las nociones de ignorancia, error e indiferencia -o desinterés-, en tanto en casos de imprudencia como de dolo el sujeto actúa con indiferencia, noción a la que también alude Ragués i Vallés en el artículo que comentamos. Asimismo, Feijoo Sánchez observa que tanto el error como la ignorancia son en alguna medida "déficits de conocimiento" (2013, p. 118). En un párrafo clarificador, en el que observa la asimilación de los casos de ignorancia a los de error, afirma:

El art. 14.1 CP dispensa obligatoriamente un trato más benigno a los que actúan con una errónea representación de los elementos del tipo, y ello con independencia de las valoraciones sobre las razones de tal error. El Código Penal español en el art. 14 sólo tiene en cuenta los motivos personales del error para distinguir entre injusto imprudente y ausencia de injusto. Sostener de lege lata que no existe un

Allí sostiene enfáticamente: "En mi opinión, las "trampas argumentativas" que oculta la "doctrina de la ceguera provocada" provienen, en gran medida, de la traducción al español de la expresión willful blindness como "ignorancia deliberada". En realidad, si tenemos en cuenta que no se trata más que de ceguera provocada (ante los hechos) se pueden apreciar mejor los peligros de una importación sin matices de construcciones de otros sistemas jurídicos. No siempre que la ceguera es consciente o voluntaria dicho conocimiento o voluntad abarca a su vez el hecho típico o todo hecho típico que se realice..... (2015, p. 13) 
error allí donde el sujeto no quería o no estaba interesado en saber $y$, por lo tanto, es responsable de su desconocimiento supone una normativización contra legem. Según el Derecho positivo español, error sobre los elementos del tipo y dolo son incompatibles, por lo que la equiparación sólo se puede hacer a través de una reforma legislativa expresa, pero no por vía judicial. (Feijoo Sánchez, 2013, p. 109)

Luego reitera que, aunque el Código Penal español no ofrece una definición de dolo, deja claro que todo error sobre la situación típica -vencible o invencible- lo excluye (2013, p. 123). En un artículo publicado con posterioridad, Feijoo Sánchez expone su opinión crítica sobre esta temática de modo más contundente aún:

Se estaría llegando de esta manera a una solución que el Código Penal sólo permite con causas de exclusión de la culpabilidad como el trastorno mental transitorio (art. 20.1 ${ }^{\circ}$ ) o la intoxicación plena (art. $20.2^{\circ}$ ), de tal manera que el error no atenúe o exonere si "hubiese sido provocado por el sujeto con el propósito de cometer el delito o hubiera previsto o debido prever su comisión", es decir, si el déficit de conocimiento es de su responsabilidad en la medida en la que deriva de una disposición jurídica intolerable o de falta de interés en cumplir las normas que implique indiferencia, desconsideración, desprecio o, incluso, hostilidad hacia las normas. Sin embargo, la propia existencia de este tipo de cláusulas referidas a la inimputabilidad en el art. $20 \mathrm{CP}$ demuestra que esta no es una solución que contemple la ley en el ámbito de la regulación del error en el art. 14 CP. No hace falta insistir en que no puede ser asumible una aplicación analógica de ciertas cláusulas relativas a la inimputabilidad en contra del reo. (Feijoo Sánchez, 2015, p. 14)

Ragués, por su parte, discrepa con estas observaciones de Feijoo Sánchez, no solo porque cuestiona la legitimidad de realizar reducciones teleológicas en aquellos elementos que excluyen la responsabilidad, sino porque -a su entender- cabe discutir incluso que los casos de quienes buscan permanecer en el desconocimiento tengan cabida en el tenor literal de la expresión "error" (2013, pp. 163-164). 
Ignorancia deliberada, ignorancia no imputable y principio de legalidad

Considero que es aguda la observación de Ragués sobre las dificultades que se presentan para calificar como "error" a las situaciones de ignorancia deliberada, ya que no parece que se tratara de situaciones donde pueda alegarse algún tipo de equívoco sobre lo que el agente debía conocer. En el caso del sistema jurídico penal argentino, justamente, no se presenta esta dificultad que mencionan las/os autoras/es, ya que expresamente se hace mención a la ignorancia en la disposición del art. 34, inciso 1, del Código Penal.

De cualquier manera, para Ragués, superar los problemas que plantea el sistema de imputación subjetiva vigente es uno de los retos más apasionantes de la ciencia penal, tarea que no debería postergarse por el hecho de contar con ciertos obstáculos -más o menos intensos- en el texto de la regulación legal. Y concluye con una afirmación más que elocuente: "El objetivo de la ciencia penal debe ser adaptar la ley al criterio que se considera más justo sin renunciar a tal tarea por el hecho de que en un determinado momento y lugar el Derecho vigente parezca acoger una solución distinta” (Ragués i Vallès, 2013, p. 165).

\section{La “ignorancia de hecho no punible” en el Código Penal argentino}

Como queda expuesto, una de las críticas que con más fuerza se ha esbozado en orden a la incorporación del instituto de la ignorancia deliberada en los sistemas jurídicos penales vigentes de tradición continental y, lo que es más relevante aún, la posibilidad de su aplicación por parte de los jueces, tiene que ver con la falta de una regulación legal expresa de dichos supuestos en los códigos penales. Esto es, existe un fuerte recelo en la posibilidad de reprochar penalmente a quien ha actuado en un estado de ignorancia que le es atribuible, si es que las normas que integran un sistema jurídico determinado no tienen prevista legalmente esa posibilidad, pues ello implicaría transgredir el principio de legalidad penal. ${ }^{6}$ Sin embargo, el término

6 En Argentina no parecieran haber sido dictadas muchas sentencias en base a esta figura doctrinaria. Dada la organización federal del país y la competencia revisora que asumen los tribunales superiores de cada provincia, incluso la Corte Suprema de Justicia de la Nación, 
"ignorancia”, en referencia a un estado mental del individuo en el momento en el que ejecuta una determinada conducta, y a diferencia de otros códigos penales, como el alemán o el español, ha sido expresamente reconocido en el Código Penal argentino, aunque en una fórmula que excluye la responsabilidad penal del sujeto que actúa bajo ese estado, si se dan ciertas circunstancias. Expresamente en el Código Penal argentino se establece que: "No son punibles: 1) El que no haya podido en el momento del hecho, ya sea por... error o ignorancia de hecho no imputables, comprender la criminalidad del acto..." (Código Penal argentino, artículo 34 inciso 1).

A diferencia de este texto, en el Código Penal alemán, ${ }^{7}$ como en el español, ${ }^{8}$ no existe ninguna disposición en la que expresamente se aluda a

es infrecuente que sus precedentes versen sobre cuestiones de hecho y prueba, en torno a las cuales suele plantearse -en el ámbito judicial- la teoría de la ignorancia deliberada. Ello dificulta la búsqueda de jurisprudencia sobre esta temática. No obstante, de una consulta acotada a los años 2018 y 2019, efectuada en la base de datos de la página web del Centro de Información Judicial, que recopila la jurisprudencia de la Corte Suprema de Justicia de la Nación y otros organismos jurisdiccionales federales y nacionales, surge que los tribunales en general son reacios a aplicar la teoría. Otros se valen de ella, afirmando que pese a la ignorancia aducida hubo conocimiento de la ilicitud de la conducta o infieren el dolo directo de otras circunstancias. Ver por ejemplo los fallos dictados por la Cámara Federal de Salta, Sala II, en “Aruquipa Calle, Eustaquia”, del 21/03/2018; la Cámara Federal de Salta, Sala I, en "Cosme Ramírez, Estefanía”, de fecha 7/05/2018; la Cámara Federal de Casación Penal, Sala IV, en "Capaccioli, María Natalia”, del 17/04/19, entre otros.

7 El artículo 16 del Código Penal alemán dice de la siguiente manera: “...Error sobre las circunstancias del hecho. (1) Quien en la comisión de un hecho no conoce una circunstancia que pertenece al tipo legal, no actúa dolosamente. La punibilidad por la comisión culposa permanece intacta. (2) Quien en la comisión de un hecho suponga circunstancias erradas, que realizarían el tipo de una ley más benigna, solo podrá ser castigado por comisión dolosa conforme a la ley más benigna", mientras que el artículo 17 establece: "Error de prohibición. Si le falta al autor en la comisión de un hecho la comprensión de lo injusto de su actuar entonces actúa sin culpa si él no pudo evitar ese error. Si el autor pudo evitar el error, entonces puede atenuarse la pena conforme al $\$ 49$, inciso 1. .”

8 El artículo 14 del Código Penal español dice así: "1. El error invencible sobre un hecho constitutivo de la infracción penal excluye la responsabilidad criminal. Si el error, atendidas las circunstancias del hecho y las personales del autor, fuera vencible, la infracción será castigada, en su caso, como imprudente. 2. El error sobre un hecho que cualifique la infracción o sobre una circunstancia agravante, impedirá su apreciación." Luego, en el artículo 20 del C.P.E. establece las causas que eximen de responsabilidad con la siguiente fórmula: "Están exentos de responsabilidad criminal: $1 .^{\circ}$ El que al tiempo de cometer la infracción penal, a causa de cualquier anomalía o alteración psíquica, no pueda comprender la ili- 
Ignorancia deliberada, ignorancia no imputable y principio de legalidad

situaciones de ignorancia. Esto parece no dejar mucho camino libre para la aplicación de la doctrina de la ignorancia deliberada. De allí los reparos que autores como Feijoo Sánchez hacen al instituto del que ha echado mano la jurisprudencia de su país, que en el caso ha atribuido responsabilidad a título de dolo eventual. El Código Penal español no contempla la falta o ausencia de conocimiento. Solo regula los distintos tipos de error, es decir, el error sobre las circunstancias que constituyen la infracción penal y el error sobre la ilicitud del hecho constitutivo de la infracción penal, los que -a su vez- pueden ser vencibles o invencibles. ${ }^{9}$ El caso del Código Penal alemán, todavía más claro, expresamente consagra que el desconocimiento de una circunstancia del tipo no es dolo y puede ser punible a título de culpa. Es decir, distingue entre "error" y "desconocimiento" y prevé consecuencias legales para el caso que se presenten uno u otro. ${ }^{10}$

Un aspecto que es importante no perder de vista es que el art. 34.1 del Código Penal argentino establece que no es punible el sujeto que al momento del hecho no haya podido comprender la criminalidad del acto por "ignorancia de hecho no imputable". Es cierto que el texto de la ley no dice que no haya podido conocer, lo que sin dudas reflejaría mejor la cualidad definitoria de la ignorancia. Por el contrario, la ley establece que

citud del hecho o actuar conforme a esa comprensión. El trastorno mental transitorio no eximirá de pena cuando hubiese sido provocado por el sujeto con el propósito de cometer el delito o hubiera previsto o debido prever su comisión. $2 .^{\circ}$ El que al tiempo de cometer la infracción penal se halle en estado de intoxicación plena por el consumo de bebidas alcohólicas, drogas tóxicas, estupefacientes, sustancias psicotrópicas u otras que produzcan efectos análogos, siempre que no haya sido buscado con el propósito de cometerla o no se hubiese previsto o debido prever su comisión, o se halle bajo la influencia de un síndrome de abstinencia, a causa de su dependencia de tales sustancias, que le impida comprender la ilicitud del hecho o actuar conforme a esa comprensión...."

9 Ragués (2013) señala, al replicar los comentarios que se efectuaron a su artículo, que si se excluyen del concepto legal de error los casos de desconocimiento provocado no parece en modo alguno que se esté incurriendo en una vulneración del principio de legalidad, pues en el derecho penal español, en el artículo 14 del Código Penal, aparece la palabra "error" pero, a diferencia de lo que sucede en el Código alemán, brillan por su ausencia expresiones como "conocimiento" o "representación".

${ }^{10}$ Jakobs (1995, pp. 313-315) explica que la ley alemana da del dolo únicamente una definición parcial y negativa: a tenor del artículo 16.1, inciso 1, StGB, si hay desconocimiento de la realización del tipo se excluye el dolo, sin que importe el motivo del desconocimiento, y el castigo sólo es relevante como imprudencia (el destacado me pertenece). 
no haya podido "comprender". Sobre esta problemática, relativa a cómo suele emplearse en forma indistinta la palabra "conocer" y "comprender", resulta interesante el comentario de Laura Manrique al artículo de Ragués, quien al exponer sus buenas razones para rechazar la equiparación entre ignorancia deliberada y dolo eventual, señala:

Por una parte, en los casos de dolo eventual el sujeto sabe exactamente aquello que hace -de hecho, él quiere hacer lo que está haciendo- pero conoce que es probable que su acción genere determinadas consecuencias dañinas que no desea. El agente actúa sin ningún error de comprensión...Por otra parte, en los casos de ignorancia deliberada el agente no sabe si está realizando determinada conducta porque carece de información relevante para comprender aquello que está haciendo. Aunque su ignorancia sea deliberada sigue siendo un caso de desconocimiento. (El destacado me pertenece). (Manrique, 2013, p. 82)

La regulación legal del error o la ignorancia de hecho no imputable fue incorporada en el proceso de sanción del Código Penal vigente, que data del año 1921, en el que se agregó la redacción del artículo 34 inciso 1, sin ningún tipo de debate al respecto. ${ }^{11}$ Se trata de una disposición que ha permanecido incólume a lo largo de los años y ha sobrepasado con éxito las numerosas reformas legislativas del Código Penal. ${ }^{12}$

Los autores argentinos si bien, en general, han distinguido ambos supuestos de exclusión de la responsabilidad, reconociendo que el error alude a falso conocimiento y que la ignorancia implica la falta o ausencia de él, han

${ }^{11}$ Sobre el proceso legislativo de redacción del art. 34 inciso 1 del Código Penal, ver (De la Rúa, 1997), quien señala: "Así, huérfana de todo debate, la materia se omite en la sanción en Diputados. Sorpresivamente la norma actual aparece sin fundamentos por la segunda comisión de Senadores y, es aceptada, también sin fundamentos, por Diputados, manteniéndose sin cambios hasta la fecha." (pp. 487-490). Soler (1992), por su parte, comenta que el texto del inciso fue tomado del Código ruso de 1903 por la Comisión Especial de Legislación Penal y Carcelaria, modificado luego por la Comisión del Senado, que cambió la frase "naturaleza y sentido de lo que hacía" por "la criminalidad del acto" (citado en la nota al pie de página 132).

12 Vale mencionar que el Proyecto de reforma del Código Penal actual al momento de este trabajo, no modifica sustancialmente el artículo citado, quitando de la expresión solamente la 
Ignorancia deliberada, ignorancia no imputable y principio de legalidad

asignado poca o nula trascendencia a ésta última, designando a la materia, cuando la estudian, genéricamente como error. De hecho, un repaso por las obras más significativas de la dogmática penal argentina clásica pone de manifiesto la escasa importancia que se le ha dedicado a la ignorancia como ignorancia de los elementos que configuran el tipo penal. ${ }^{13}$

Para De la Rúa (1997, pp. 490-502) la falta de conocimiento implica, en última instancia, un conocimiento falso, pero aclara el autor que ello es así en la medida en que se atienda al contenido general del conocimiento del sujeto en un momento dado, ya que si se circunscribe, en cambio, al concreto saber en relación a los aspectos del hecho, la distinción es viable. Asimismo, señala que otra de las condiciones que debe reunir el error para eximir de culpabilidad es su calidad de "invencible", "inculpable" o "inevitable", equiparando todos estos términos y otorgándole el sentido de que el error o la ignorancia no deben provenir del dolo o la culpa del autor.

Sebastián Soler (1992) es categórico en su obra cuando afirma que: "La distinción entre ignorancia y error no es fundamental en el sentido de sus consecuencias jurídicas..." (p. 98). Luego distingue conceptualmente a la primera como "puro no saber" y al segundo como "saber mal". Y, siendo en realidad difícil un caso de ignorancia pura, ya que casi siempre se dará -para el autor- la hipótesis del obrar equivocadamente, se ocupa de hablar con preferencia del error. ${ }^{14}$ No obstante, al explicar la doctrina del error de derecho penal y de derecho no penal, sí se refiere a la ignorancia, aunque adquiere relevancia nuevamente solo en orden a la ignorancia del derecho o de las circunstancias que hacen a la ilicitud de la conducta. Señala que la ignorancia del derecho penal no excusa y la ignorancia del derecho

palabra "de hecho", pero manteniendo el término "ignorancia" como supuesto que excluye la punibilidad.

${ }^{13}$ En cambio, si se le ha dedicado más estudio a la ignorancia como ignorancia de la antijuridicidad de la conducta. Vale recordar aquí que la fórmula del Código Penal argentino utiliza el término error e ignorancia sin especificar a qué tipo de error o ignorancia se refiere. Por ello en general la doctrina trata estas causas como excluyentes tanto de la tipicidad, como de la antijuridicidad y la culpabilidad.

${ }^{14}$ En sentido similar, Núñez (1960, p. 94). Zaffaroni, Alaggia y Slockar (2005, p. 532) tampoco distinguen, entre las causas que excluyen la tipicidad, al error de la ignorancia, más que para definirlos. 
no penal equivale a ignorancia de hecho. ${ }^{15}$ Sin embargo reconoce que esa doctrina, aplicada por los tribunales alemanes, plantea para los argentinos un problema difícil, por cuanto nuestra ley se refiere expresamente a la ignorancia de hecho (Soler, 1992, p. 107).

Vemos aquí que el significado asignado al texto desde una interpretación literal, o de acuerdo a los usos comunes del lenguaje, relacionado a circunstancias relativas a los hechos, que constituía un problema para los propósitos conceptuales de Soler, relativos a la ignorancia del derecho, es por el contrario una posibilidad de argumentar en favor de la aplicación del texto de esa disposición para regular situaciones en que se presente una situación de ignorancia deliberada o de ignorancia de hecho imputable (Guastini, 2014, p. 109).

Ahora bien, más allá de las poca atención dedicada a la "ignorancia de hecho no imputable" como supuesto que excluye de pena, resulta difícil imaginar que la dogmática penal clásica argentina hubiera tenido en mente, al analizar la disposición penal citada, casos como los que plantea Ragués i Vallès en su artículo. Sin embargo, ello no debe ser óbice para la elaboración de nuevas ideas y propuestas dogmáticas en torno a la atribución de responsabilidad en supuestos de ignorancia deliberada, teniendo en cuenta lo expresamente dispuesto en el derecho positivo argentino. Máxime si existe una disposición legal específica que hace referencia a un estado mental de desconocimiento o ignorancia del individuo al momento del hecho y de la cual los doctrinarios extraen los presupuestos para aplicar sus teorías del dolo. ${ }^{16}$ Tomando en cuenta dicha mención expresa sobre la no puni-

15 "Nadie puede decir, pues, que ignore la prohibición de circular moneda falsa, pero así como puede ignorar la falsedad de determinado billete (error de hecho), puede ignorar que una ley financiera ha sacado de la circulación determinado valor (ignorancia de derecho extrapenal) y esta última forma es exactamente ignorancia de hecho, porque es ignorancia de circunstancias que hacían a la calificación del hecho realizado". (Soler, 1992, pp. 105-106)

${ }^{16}$ Para Zaffaroni, Alaggia, Slockar (2005), quienes sostienen que el dolo es conocimiento y voluntad, no pareciera ser posible atribuir responsabilidad a título de dolo: “...Cuando el agente no sepa -por desconocimiento de alguno de esos elementos necesarios- qué es lo que hace, o quiera hacer algo diferente..." (p. 527). Estos autores extraen de la fórmula del art. 34, inc. 1 del C.P. que, en el nivel de la tipicidad, el dolo presupone en el autor conocimientos efectivos y actuales para un plan de realización de un tipo objetivo. Y afirman que el conocimiento que exige el dolo se distingue del que se exige para el resto del delito -en el que 
Ignorancia deliberada, ignorancia no imputable y principio de legalidad

bilidad de la ignorancia de hecho no imputable, entiendo que es plausible sostener que la ignorancia de hecho imputable, deliberada o provocada, sí resulta punible en el sistema jurídico argentino.

A la luz de casos como los que trae a estudio Ragués i Vallès en su obra, la dogmática penal argentina tiene frente a sí el desafío de analizar bajo qué supuestos sería punible una persona que actuó ignorando alguna circunstancia de hecho que le impidió conocer la criminalidad de su conducta, siempre que ese estado de ignorancia o desconocimiento le hubiera sido "imputable"; como así también qué implicancias tendría ello en nuestro sistema jurídico, en torno a la teoría de la willful blindness, derivada del derecho anglosajón.

Desde la dogmática penal clásica argentina, se ha negado que el error imputable sea el reverso del dolo. Soler abona la teoría de que el error, aunque sea imputable y siempre que sea esencial, destruye el dolo en todo caso. Sería para él una lamentable confusión afirmar que la responsabilidad por el hecho cometido por "error imputable" es idéntica a la del hecho cometido sin error alguno, pues todos los delitos por culpa quedarían reducidos a delitos dolosos, dado que en el fondo de casi todos ellos hay un error que con mayor diligencia se pudo evitar (Soler, 1992; Núñez, 1960). Pero, claro está, Soler no se ocupó de la "ignorancia de hecho imputable". De cualquier manera, y contraponiendo la postura de Ragués, para quien la falta de una definición expresa de dolo habilitaría flexibilizar su aplicación a casos de ignorancia deliberada, para el dogmático argentino pareciera ser justamente esa ausencia de definición de dolo y culpa en el sistema legal argentino lo que impide aplicar el primero a casos de error imputable, es decir, en definitiva, extender o flexibilizar su utilización (Soler, 1992, p. 116).

En este sentido, traigo a colación la expresión de Ragués al concluir el artículo que inicia la discusión, en virtud de la cual considera que en ordenamientos como el argentino o el español no parece que existan problemas insalvables de legalidad para incluir estos supuestos en el concepto de dolo, ya que se trata de una expresión muy abierta, de carácter eminentemente técnico y de la que no existe definición legal. Y, si bien no es posible afirmar 
que haya tenido en mente la referencia expresa a la "ignorancia" del artículo 34.1 del Código Penal argentino, aclara que conviene tener presente que la inclusión de semejantes casos en el concepto de dolo impedirá seguir definiendo esta figura a partir del conocimiento. Consecuencia que luce plausible si se tiene seriamente en cuenta aquella norma para describir qué conductas son penalmente relevantes para nuestro ordenamiento jurídico y qué parámetros deben ser valorados para reprocharlas, sea el reproche a título de dolo o de imprudencia. ${ }^{17}$

\section{Ignorancia no imputable y motivos}

¿Qué implica que la ignorancia no deba ser imputable para que opere la causal de exclusión de la punibilidad? Ragués i Vallès formula una pregunta similar: “...qué cabe entender por haber generado de manera imputable un contexto de exoneración con el objeto de eludir la norma...” (2013, p. 155); incluso utilizando la misma expresión lingüística - "imputable”- que emplea el texto argentino. Entiende que para equiparar los casos de ignorancia deliberada al dolo, en primer lugar, el sujeto debe haber obrado en la sospecha de estar llevando a cabo una acción u omisión potencialmente lesiva en el futuro para algún interés indeterminado; en segundo lugar, el sujeto debe haber obrado con una "especial motivación", es decir, debe haber permanecido en la ignorancia con el propósito de "construirse" una excusa que lo exonere en el supuesto de acabar produciéndose tal lesión (Ragués i Vallés, 2013, p. 156). El autor asigna mayor contenido expresivo a la conducta de quien ignora deliberadamente que a la de quien actúa bajo

17 Pérez Barberá (2011) afirma que el derecho penal positivo argentino no constituye impedimento alguno para la explicación del dolo como un concepto estrictamente normativo, no equiparable con el de conocimiento. Pues para el autor, el Código Penal dice únicamente que no es punible quien actúa con error de hecho no imputable (art. 34, inc. 1º C.P.). Y qué sea un "error de hecho no imputable" es algo que, en todo caso, sabremos no por lo que diga la ley o la naturaleza, sino por lo que determine el pertinente desarrollo dogmático de ese concepto legal, que en nuestro país no es forzoso que se elabore a partir del par psicológico “conocimiento/desconocimiento". Desde su interesante propuesta teórica, Pérez Barberá dice que bien podría sostenerse que un error de hecho no imputable al autor sólo puede estar conformado por un desconocimiento no irracional del riesgo creado (2011, p. 51). 
Ignorancia deliberada, ignorancia no imputable y principio de legalidad

error, circunstancia que según él habilitaría a dispensar a las primeras un tratamiento punitivo similar al dolo eventual. ${ }^{18}$

Desde un punto de vista expresivo no solo cabe valorar el desconocimiento, sino los motivos que han llevado a él: no en vano, un observador medio nunca diría que quien ha querido mantenerse en la ignorancia se encuentra en una situación de error, máxime si partía de la sospecha inicial de que su comportamiento podía lesionar algún interés -ciertamente no concretado- colectivo o de otro sujeto (El destacado me pertenece). (Ragués i Vallés, 2013, p. 28)

En este punto, resulta interesante la discusión planteada por Puppo (2013). Para este autor debe distinguirse entre la "ignorancia de la ley o el derecho penal" y la "ignorancia de los elementos del tipo"; ${ }^{19}$ aunque de cualquier modo sospecha que, en el contexto real de la valoración penal de la ignorancia deliberada de los hechos que definen el tipo penal, los dos elementos son indisociables. Esta indisociabilidad depende, en su opinión, del elemento que -según Ragués- proporciona la justificación más plausible de la distinta respuesta penal para los delitos dolosos y los imprudentes, es decir, el mayor contenido expresivo de la conducta tradicionalmente dolosa, que el autor enuncia como una crasa indiferencia hacia los valores protegidos por la norma penal (Puppo, 2013; Ragués i Vallés, 2013; Luban, 1999).

El caso de crasa indiferencia puede traducirse por la ignorancia de la ley penal y por lo tanto por la ignorancia de los elementos del tipo penal, cuyo desconocimiento deliberado no puede ser relacionado con una actitud de zorro, porque, desconociendo el

${ }^{18}$ Yaffe (2106) presenta una teoría para justificar el reproche penal en los casos de ignorancia deliberada, considerando la importancia de los estados mentales en la atribución de culpabilidad. Su teoría intenta explicar bajo qué circunstancias es correcto aplicar el principio de la ignorancia deliberada y equiparar el castigo al de los casos en los que se actúa con conocimiento y de forma intencional, teniendo en cuenta, entre otros aspectos, el desprecio que manifiesta el autor por los valores o intereses de terceros.

19 Para aproximarse a esta temática, vinculada a la ignorancia de las normas legales y morales, su relación con la ignorancia de los hechos y la ignorancia deliberada, desde una perspectiva de la filosofía moral, recomiendo la lectura de la obra de (Husak, 2016). También los artículos de (Yaffe, 2017) y (Zimmerman, 2017). 
tipo penal, el sujeto no tiene la posibilidad de dirigir activamente su ignorancia. Si no conozco los hechos a los cuales el derecho penal imputa consecuencias penales, no puedo decidir ignorarlos para evitar tales consecuencias. Los casos de crasa indiferencia parecen difícilmente sancionables, a menos que, a partir de una distinción sustantiva entre (al menos) dos categorías de valores protegidos, se considere que un cierto tipo de crasa indiferencia, más allá de haber provocado la ignorancia de ciertos elementos del tipo penal, merece una sanción. (Puppo, 2013, pp. 60-61)

Y recordando la distinción kelseniana entre mala prohibita y mala in se a partir de ciertos ejemplos (Puppo, 2013, p. 60), concluye que el caso paradigmático de ignorancia deliberada culpable sería el de quien, a partir de un conocimiento detallado de la norma penal y mediando exclusivamente un propósito o motivo malvado, se esfuerza por ignorar todo lo que debe ser ignorado para evitar la aplicabilidad de la norma penal. Es decir, no cualquier caso de ignorancia resultaría punible. Al menos no uno que implique ignorar las consecuencias jurídico-penales de la conducta, sino que es preciso que el sujeto sepa que su desconocimiento sobre ciertos elementos de aquella -los necesarios para otorgarle relevancia jurídico-penal-, traerá aparejado un beneficio para él. Precisamente porque -en la idea de Puppo- conoce o sabe las posibles consecuencias legales que acarrea emprender la acción y, en esos casos, la reprochabilidad de la conducta podría ser hasta superior que en los casos de dolo tradicional. Sin embargo, para el autor, el elemento clave no será la prueba sobre los elementos cognitivos (la ignorancia) y teleológicos (el beneficio) en los que se centra el núcleo de la teoría de la ignorancia deliberada sostenida por Ragués, sino que, como en definitiva el reproche dependerá de los motivos que el autor tuvo para actuar, lo relevante será un juicio de valor moral sobre dichos motivos, que realizará el juez sobre el acusado. Distingue para ello entre la condena moral del bad man y la excusabilidad moral del ignorante buen samaritano.

Desde otra mirada, al comentar el artículo de Ragués, Manrique dedica un apartado a la relación de la ignorancia deliberada y los motivos, sosteniendo que coincide con el autor en cuanto a que los motivos son relevantes para la atribución de responsabilidad. En una publicación posterior, sos- 
Ignorancia deliberada, ignorancia no imputable y principio de legalidad

tiene -más categóricamente- que: “...para afirmar que hay ignorancia deliberada el agente debe haber tenido (y por tanto se debe probar) un motivo específico para mantenerse en la ignorancia..." (Manrique, 2016, p. 93). Sin embargo, considera que ello implica un desafío para las concepciones epistémicas del dolo, es decir, aquellas que reconducen la noción de dolo sólo al conocimiento e insisten en una figura depurada de elementos volitivos, tal como la que suscribe Ragués. ${ }^{20}$ La autora también pregunta qué justificación podría invocarse para descartar los motivos y deja de lado la cuestión acerca de si existe una disposición jurídica específica que imponga o excluya la necesidad de tener en cuenta los motivos para la ignorancia deliberada. Pues, no obstante la existencia o no de ella, “...el Estado debe probar que la ignorancia fue deliberada y, por esa razón, podría generarse la ilusión de que la persecución penal no se desentiende de la prueba de los estados mentales..." (El destacado es de la autora) (Manrique, 2013, p. 93). Siguiendo el planteo de Luban, opina que los motivos son relevantes no solo para calificar la ignorancia sino también a la hora de establecer el grado de responsabilidad. Así, sostiene que no parece adecuado resolver el problema a 'todo o nada': algunos casos de ignorancia serán evidentemente similares a complejas acciones dolosas, mientras que algunos otros casos tendrán una indudable semejanza con la imprudencia (Manrique, 2013, p 96; Luban, 1999, p. 969).

La relevancia que poseen las motivaciones de quien decide llevar a cabo una conducta contraria a la ley para definir los casos de ignorancia deliberada constituye una interesante perspectiva desde la cual analizar el texto de la ley argentina. Como ya se dijo, el art. 34, inciso $1^{\circ}$ del Código Penal exige que, para eximir de pena a un individuo, la ignorancia no le debe haber sido imputable. Sin embargo, no especifica qué debe entenderse por “(no) imputable”. El término parecería referir tanto a un estado provocado por causas fortuitas, como al generado por conductas de terceros y también al provocado por el propio individuo. En este último supuesto, y siguiendo

20 Al replicar la crítica de Manrique en el sentido de que su postura no tendría en cuenta las razones por las que actuó el sujeto, Ragués (2013, pp. 156-157) asegura haber salvado este reparo con la incorporación de aquella "especial motivación" que debe estar presente en el sujeto que ignora deliberadamente y que resulta un elemento adicional que debe ser probado en el proceso. 
el razonamiento de las/os autoras/es, no veo impedimento para excluir del análisis a los motivos a los efectos de definir el reproche. Incluso su valoración deriva, en el sistema jurídico penal argentino, de otra disposición (artículo 41 C.P.) que dispone que, a los fines de fijar la condena, el juez debe valorar, entre otras cosas, la conducta precedente del sujeto y los motivos que lo llevaron a delinquir. Como sea, lo cierto es que la disposición del artículo 34.1 del C.P. ofrece un abanico de posibilidades interpretativas que, junto a otras normas jurídicas del sistema, permitiría definir los contornos de la figura de la ignorancia imputable y establecer qué tipo o grado de reproche correspondería aplicar en esos casos.

\section{Conclusión}

En el presente trabajo he procurado reconstruir las ideas desarrolladas en Discusiones XIII sobre ignorancia deliberada en el ámbito del derecho penal, en especial, aquellas que expresan una franca preocupación de las/ os juristas en torno a la existencia de disposiciones legales expresas que justifiquen la aplicación de la figura en los sistemas jurídicos de tradición continental europea.

Tomando esa inquietud legítima, propia de la dogmática penal, he propuesto el análisis de los casos de ignorancia deliberada a la luz de una disposición legal del Código Penal argentino, que regula específicamente las propiedades que debe reunir la conducta de un individuo que actúa en un estado de ignorancia para merecer reproche penal. Vemos que, en general, la mayoría de los autores de dogmática han tomado la disposición del art. 34, inciso 1, del Código Penal argentino para avalar sus definiciones de dolo y han prestado una mayor atención al texto de la norma en cuanto se refiere al error no imputable como excluyente de aquél. Un ligero repaso por las obras de dogmática penal clásica argentina nos muestra que, pese a ser supuestos diferentes, no le han asignado a la ignorancia una función tan relevante como al error. Y si bien se ha estudiado la incidencia de ese estado mental cuando recae sobre la ilicitud de la conducta, poca o nula trascendencia le han brindado a la ignorancia cuando ésta se refiere a los elementos del tipo penal. Lejos han estado las elaboraciones de aquellos 
Ignorancia deliberada, ignorancia no imputable y principio de legalidad

dogmáticos argentinos que hemos citado en este trabajo de la figura de la willful blindness del derecho anglosajón o de la ignorancia deliberada que aplican los tribunales españoles y que defiende Ragués i Vallès.

Tampoco he hallado obras dogmáticas actuales en las que se haya intentado elaborar la posibilidad de justificar la regulación de esos supuestos de ignorancia deliberada a partir del texto del artículo 34.1 del C.P. sobre el que se puso atención en este trabajo. No obstante, más que un obstáculo, ello debiera constituir un desafío para las/os autoras/es contemporáneos en el desarrollo de nuevas propuestas interpretativas, en las que se tengan en cuenta nuevas modalidades delictivas y se tomen con seriedad las excusas que se brindan en el proceso. En esa tarea, entiendo que las/os autoras/es de dogmática no deberían perder de vista que en el derecho positivo argentino existe una regulación legal expresa de la ignorancia de hecho como estado mental que excluye el reproche penal, siempre que ese estado de ignorancia no sea imputable o atribuible.

Esta observación es fruto de una preocupación que he hecho explícita en estas páginas y que se vincula a la necesidad de que en los estudios de dogmática penal no se pierda de vista la relevancia de los textos de los ordenamientos jurídicos particulares en las propuestas que se realizan, en especial, por la importancia que tienen esos textos en la efectiva solución normativa que brindan los tribunales en los casos concretos.

El conjunto de interrogantes que se plantean alrededor de la norma legal sobre la que se ha hecho foco, respecto a qué debe entenderse por "ignorancia de hecho no imputable" y de qué manera debiera ser reprochada una conducta llevada a cabo en un estado de "ignorancia imputable", merece un examen detenido y sistemático de aquella disposición por parte de quienes realizan estudios de dogmáticas de derecho penal.

Nino ha señalado que una función latente, extraordinariamente relevante de la dogmática, es la de adecuar las normas jurídicas a determinadas pautas que establecen soluciones valiosas. El dogmático cumple con la importante misión de ir adecuando el derecho legislado a las cambiantes circunstancias fácticas y a las variaciones en las preferencias sociales (Nino, 1989, pp. 33-34). El debate generado en Discusiones XIII es un excelente punto de partida para retomar las ideas plasmadas, apuntar las críticas y realizar un estudio actual, especialmente en el sistema jurídico argentino, 
sobre las posibilidades de considerar regulados actualmente por el texto del artículo 34.1 del Código Penal los supuestos que se identifican como de ignorancia deliberada y, en ese caso, reflexionar acerca de las soluciones normativas que podrían extraerse justificadamente de esa disposición.

\section{Bibliografía}

De la Rúa, J. (1997). Código Penal Argentino. Parte General. Bueno Aires, Argentina: Depalma.

Feijoo Sánchez, B. (2013). Mejor no saber... más. Sobre la doctrina de la ceguera provocada ante los hechos en Derecho Penal. Discusiones, 13, 101-138.

Feijoo Sánchez, B. (2015). La teoría de la ignorancia deliberada en Derecho Penal. Una peligrosa doctrina jurisprudencial. InDret, 3(15).

Greco, L. (2013). Comentario al artículo de Ramón Ragués. Discusiones, 13, 67-78.

Guastini, R. (2014). Interpretar y Argumentar. Madrid, España: Centro de Estudios Constitucionales.

Husak, D. y Callender, C. (1994). Wilful Ignorance, Knowledge, and the 'Equal Culpability' Thesis: a Study of the Deeper Significance of the Principle of Legality. Wisconsin Law Review, 29, 29-69.

Husak, D. (2016). Ignorance of Law. A philosophical inquiry. Oxford, Inglaterra: Oxford University Press.

Jakobs, G. (1995). Derecho Penal. Parte General. Fundamentos y teoría de la imputación. Madrid: Marcial Pons.

Manrique, M. L., Navarro, P., Peralta, J. M. (2010). La relevancia de la dogmática penal. Córdoba, Argentina: Publicaciones de la Universidad Blas Pascal.

Manrique, M. L. (2013). ¿Mejor no saber? Algunas consideraciones sobre la atribución de responsabilidad penal en caso de ignorancia. Discusiones, 13, 79-100.

Manrique, M. L. (2016). Motivos para sospechar, deber de conocer e ignorancia deliberada. Iter Criminis, 87-104. 
Nino, C. S. (1989). Consideraciones sobre la dogmática jurídica. México: Universidad Nacional Autónoma de México, Instituto de Investigaciones Jurídicas.

Nuñez, R. (1960). Derecho Penal argentino. Parte General (2). Buenos Aires, Argentina: Bibliográfica Omeba.

Pérez Barberá, G. (2011). El dolo eventual. Buenos Aires, Argentina: Hammurabi.

Puppo, A. (2013). Comentario a Mejor no saber. Sobre la doctrina de la ignorancia deliberada en Derecho Penal, de Ramón Ragués i Vallès. Discusiones, 13, 39-66.

Ragués i Vallès, R. (2013). Mejor no saber. Sobre la doctrina de la ignorancia deliberada en Derecho Penal. Discusiones, 13, 11-38.

Ragués i Vallès, R. (2013). A modo de contrarréplica: la ignorancia deliberada y su difícil encaje en la teoría dominante de la imputación subjetiva. Discusiones, 13, 139-166.

Soler, S. (1992). Derecho Penal Argentino (2). Buenos Aires, Argentina: Tea. Yaffe G. (2016). The Point of Mens Rea: The Case of Willful Ignorance. Crim Law and Philos. Doi: 10.1007/s11572-016-9408-3.

Yaffe, G. (2017). Is Akrasia Necessary for Culpability? On Douglas Husak's Ignorance of Law. Crim Law and Philos. Doi:10.1007/s11572-017-9443-8. Zaffaroni, E., Alaggia, A. y Slockar, A. (2005). Derecho Penal - Parte General. Buenos Aires, Argentina: Ediar.

Zimmerman, M. (2017). Recklessness, Willful Ignorance, and Exculpation. Crim Law and Philos. Doi: 10.1007/s11572-017-9424-y. 